\title{
Erratum to: Techniques for Evaluating the Differences in Multiregional Input-Output Databases
}

\author{
Anne Owen
}

\section{Erratum to:}

\section{A. Owen, Techniques for Evaluating the Differences in Multiregional Input-Output Databases, Developments in Input-Output Analysis, DOI 10.1007/978-3-319-51556-4}

In the original version of the book, "Endorsement" is to be included in the front matter. The erratum book has been updated with the change.

The updated original online version for the book frontmatter found at http://dx.doi.org/10.1007/978-3-319-51556-4

\footnotetext{
A. Owen $(\bowtie)$

University of Leeds, Leeds, UK

e-mail: a.owen@leeds.ac.uk 